\title{
Sustainable Housing Development in Conditions of Changing Living Environment
}

\author{
Natalya Safronova ${ }^{1,{ }^{*}, E k a t e r i n a}$ Nezhnikova ${ }^{2}$ and Azamat Kolhidov $^{2}$ \\ ${ }^{1}$ Russian Presidential Academy of National Economy and Public Administration, 82/5, Prospect \\ Vernadskogo, Moscow, 119571, Russia \\ ${ }^{2}$ Moscow State University of Civil Engineering, 26, Yaroslavskoyeshosse, Moscow,129337, Russia
}

\begin{abstract}
Article provides the organization-economic mechanism of sustainable development of the housing, the main content of which is formalized reflection of quality, environmental friendliness and cost of housing stock in conditions of changing living environment. Considered underlying principles of the sustainable development concept and considered experience of the developed countries at formation of the sustainable development of the housing allowed to analyze the main documents in which concept of sustainable development in Russian Federation found its reflection. Usage of the offered organizationaleconomic mechanism allows to create qualitative and green living environment, raise the level of quality of life and competitiveness of the housing stock, workforce productivity, and human longevity.
\end{abstract}

\section{Introduction}

The concept of "sustainable development" was formulated in 1987 in the report "Our Common Future", which was prepared by the World Commission on Environment and Development of the United Nations. The term "sustainable development" was proposed to realize such development that meets the current needs of the people without compromising the needs of future generations. This concept contains two components: needs of people (primarily marginal population) and restrictions associated with the level of technology and organization of society improvement and ability of the environment to meet their needs today and tomorrow [1].

Experience of development of the different branches of national economics a number of industrialized countries was studied with formation of mechanism of sustainable housing development in changing environmental conditions. This experience includes creation of the balanced habitat with a high quality of life of the citizens. In modern understanding sustainable development involves self-development the citizens and territories, natural regulation, resistance to extreme climatic events, and resource savings.

Sustainable development means creation of certain level of the ecosystem improvement, the development of some standards of access to clean air and water, centralized sanitation and heat supply, etc. In this case, the "green" infrastructure should be an integral part of this

*Corresponding author: safronova@,ranepa.ru 
standard [2]. The interest of the public-private partnership to the improvement of such infrastructure and cost of the design, supply of materials, structures, machinery, and the building itself - all of this is directly linked to market mechanisms. Good environmental factors significantly increase the price of the housing projects located on the such territories. That's why the comparison of the competitiveness of the housing stock is the noteworthy aspect. Such indexes as "quality of the housing stock", "ecological housing", "housing consumption cost" are taken for based calculations [3].

\section{Methods}

Concept of sustainable development is based on the following principles:

1. principle of fairness and justice;

2. principle of conservation of nature;

3. principle of unity of thinking;

4. principle of global thinking - is to act locally.

Principle of fairness and justice is one of the most important principles of sustainable development, which is oriented on ensuring of high quality of life for all people on the planet, including future generations.

Nowadays many people are unable to meet their vital needs for food, clothing, shelter, employment adequately (people of the developing countries). Part of the developed countries population lives "beyond their means". This principle suggests that opportunities and responsibilities are equitably distributed between countries and people within each country. Principle of fairness and justice implies that we can't live on borrowed from the future generation time, depleting resources and degrading the quality of the environment. Our duty is to maintain the conditions and resources for the future generations, that could have the opportunity to meet their own needs. Principle of conservation proves the organization of vital processes in such a way that they don't lead to irreversible changes in biosphere. This is possible only with reducing of the anthropogenic impacts on the environment. Characteristic of human-induced disturbances is anthropogenic load. Humaninduced disturbances can be compensated only by the urge to achieve a balanced development of the three aspects of the environment, they are environmental, economic and social [4]. Principle of unity thought suggests that the solution of the modern problems is the sustainable improvement of the quality of life of present and future generations, which takes place only with a comprehension of complexity of social, ecological and economic system. Within this framework sustainable becomes such society development, where social, environmental and economic issues are addressed comprehensively. Principle of globally thought is to act locally and analyze over time. This means that its necessary to keep in mind the long-term prospective analyzing the past experience in order to have the comprehension of causes of the problem and its possible solutions.

\section{Results}

Sustainable development in the modern interpretation means creation of certain level of the ecosystem improvement, the development of some standards of access to clean air and water, centralized sanitation and heat supply, etc. In this case, the "green" infrastructure should be an integral part of this standard.

Concept of sustainable development in the Russian Federation is currently reflected in the following documents:

1. Decree of the President of the Russian Federation from June 4, 2008 N 889 "On some measures of improvement of the energy and environmental efficiency of the Russian 
economy" in which in order to reduce the energy intensity of the GDP of the Russian Federation to 2020 not less than on 40 percent in comparison with 2007 and to ensure the rational and environmentally responsible usage energy and power resources enacted:

- to implement measures that will be aimed at improvement of the energy and environmental efficiency of such industries as electric power, construction, housing, communal services and transport;

- to ensure the unified principles of development of standards of permissible impact on the environment;

- to introduce to the State Duma acts, which provide mechanisms of encouragement for business entities which use energy-saving and green technologies;

- to introduce to the State Duma projects of Federal Laws aimed at strengthening of the responsibility of business entities for non-compliance of norms of permissible impact on the environment in order to stimulate the transition to energy-saving and green technologies;

- to provide the allocation of public funds which are needed to promote the projects of usage of renewable energy sources and clean production technologies;

-to include foundations of ecological knowledge in the Federal State educational standards for basic general education.

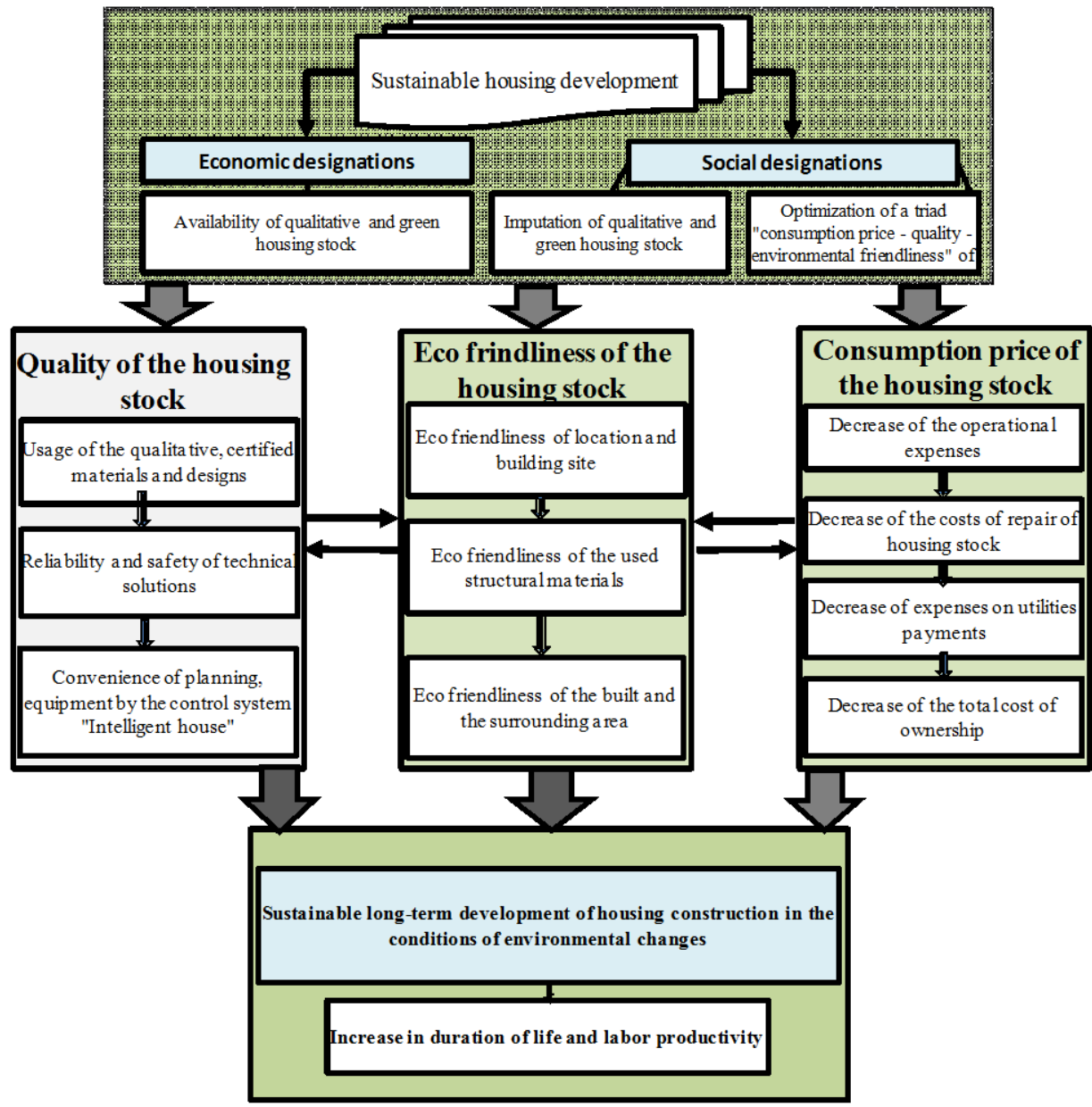

Fig. 1. Organizational-economic mechanism of sustainable housing development 
2. Presidential Decree from 30.09.2013, No. 752 "On the reduction of greenhouse gas emissions" in which for implementation of the Climate Doctrine of the Russian Federation enacted:

- to ensure reduction of greenhouse gases to a level of no more than $75 \%$ from the volume of pointed emissions to $2020[5,6]$;

- to approve the plan of activities for the established greenhouse gas emissions with foreseen reduction of greenhouse gas emissions by the sectors of economy.

3. Federal Law No. 261-FZ "On energy saving and increase of energy efficiency," according to which $[5,7]$ :

- owners of premises in apartment buildings are obliged to provide housing facilities with meters of water, natural gas, thermal energy and electric energy;

-owners of premises in apartment houses are obliged to incur expenses for activities on conservation of energy and energy efficiency improvement.

On the basis of the above we consider it necessary to take advantages of the multidisciplinary approach for creation of the organizational-economic mechanism of sustainable development of housing construction. It allows to find a solution to the problem of sustainable development not in the sphere of some niche specialization, but on the crossroads of economic and environmental sciences. We consider socio bioengineering a very prospective direction in this context [8].

\section{Discussion}

The foregoing allows the author to offer organizational and economic mechanism for sustainable housing development (Fig. 1). The main content of the proposed mechanism is formalized reflection [9]:

- of the quality of housing stock (destination indicators, reliability, ergonomics, security, aesthetics);

- of the ecological housing (green location, usage of building materials and technologies, surrounding area, usage of green technologies);

- of the housing price (actual cost and laid margin).

\section{Conclusion}

Sustainable housing development subject to widespread implementation of quality and environmental performance is the urgent problem for our country. Bad environment reduces innovative activity and life expectancy of the population. Based on research and experience of developed countries it can be proven that the creation of high-quality and green habitat allows to improve the standard of living, productivity and life expectancy.

\section{References}

1. N. Ivanov. System-Modern Applied Science,10(1), 47-51 (2016)

2. N. Ivanov. Procedia Engineering,153, 228-231 (2016)

3. N. Ivanov. Appl. En. Res., 10, 42415-42418 (2015)

4. Yang, B., Xu T, Shi L. Journal of Cleaner Production, 141, 868-880 (2017)

5. Report of the United Nations Conference on Environment and Development. Rio de Janeiro, 3-14 June 1992 T.I. United Nations, New York, 528 (1993)

6. Charter for sustainable development of European cities. The documents of the European Conference on Sustainable Cities. Olsborg, 28 (1994) 
7. X.Zheng, E.C.Hui. Land Use Policy 56, 189-196 (2016)

8. J. He, J. Wu. Regional Science and Urban Economics, 57, 46-53(2016)

9. Dieci R., F.Westerhoff. Journal of Economic Dynamics and Control, 71, 21-44(2016) 